\title{
Psychological control by parents is associated with a higher child weight
}

\author{
Citation for published version (APA):
}

Rodenburg, G., Kremers, S. P., Oenema, A., \& van de Mheen, D. (2011). Psychological control by parents is associated with a higher child weight. International Journal of Pediatric Obesity, 6(5-6), 442-449. https://doi.org/10.3109/17477166.2011.590203

Document status and date:

Published: 01/10/2011

DOI:

10.3109/17477166.2011.590203

Document Version:

Publisher's PDF, also known as Version of record

\section{Please check the document version of this publication:}

- A submitted manuscript is the version of the article upon submission and before peer-review. There can be important differences between the submitted version and the official published version of record.

People interested in the research are advised to contact the author for the final version of the publication, or visit the DOI to the publisher's website.

- The final author version and the galley proof are versions of the publication after peer review.

- The final published version features the final layout of the paper including the volume, issue and page numbers.

Link to publication

\footnotetext{
General rights rights.

- You may freely distribute the URL identifying the publication in the public portal. please follow below link for the End User Agreement:

www.umlib.nl/taverne-license

Take down policy

If you believe that this document breaches copyright please contact us at:

repository@maastrichtuniversity.nl

providing details and we will investigate your claim.
}

Copyright and moral rights for the publications made accessible in the public portal are retained by the authors and/or other copyright owners and it is a condition of accessing publications that users recognise and abide by the legal requirements associated with these

- Users may download and print one copy of any publication from the public portal for the purpose of private study or research.

- You may not further distribute the material or use it for any profit-making activity or commercial gain

If the publication is distributed under the terms of Article $25 \mathrm{fa}$ of the Dutch Copyright Act, indicated by the "Taverne" license above, 


\title{
ORIGINAL ARTICLE
}

\section{Psychological control by parents is associated with a higher child weight}

\author{
GERDA RODENBURG ${ }^{1,2}$, STEF P. J. KREMERS ${ }^{3}$, ANKE OENEMA ${ }^{2}$ \\ \& DIKE VAN DE MHEEN ${ }^{1,2}$ \\ ${ }^{1}$ IVO Addiction Research Institute, Rotterdam, ${ }^{2}$ Erasmus Medical Center, Rotterdam, ${ }^{3}$ Department of Health Promotion, \\ Maastricht University, Maastricht, the Netherlands
}

\begin{abstract}
Objective. In this examination of the association between parenting style and child weight, the neglected concept of 'psychological control' has been added to the generally accepted parenting dimensions 'support' and 'behavioural control'. Also explored is whether the potential association between parenting and child weight is moderated by socio-demographic variables (child's age/ethnicity, and parent's education level). Methods. A cross-sectional study was performed among 1,665 parent-child dyads. The children's mean age was 8 years. Their height and weight were measured to calculate their body mass index (BMI). Parents completed a questionnaire to measure the three parenting dimensions. Based on these dimensions, five parenting styles were defined: the authoritative, permissive, authoritarian, neglecting and rejecting parenting style. Child BMI z-scores were regressed on parenting style, adjusting for parental BMI, child ethnicity, and parent's education level. Results. Rejecting parenting, characterized by high psychological control, low support and low behavioural control, is the only parenting style significantly related to child BMI $z$-scores $(\beta=0.074, p<0.001)$. The positive association was not moderated by socio-demographic variables. Conclusions. By adding the dimension of psychological control to the concept of parenting, this study has further elucidated the mechanisms whereby parenting may affect child weight. Demonstrating that 'rejecting parenting' is associated with a higher child weight, emphasizes the need for longitudinal studies in which parenting style is measured three-dimensionally. Potential mediating effects of parental feeding style and children's eating style, as well as age moderation, should be included in these studies.
\end{abstract}

Key words: Parenting style, psychological control, support, behavioural control, children, BMI, overweight

\section{Introduction}

In the Netherlands, as in many other countries, the prevalence of overweight and obesity among children is increasing rapidly $(1,2)$. Since the 1990 s, in behavioural science attention has broadened from individual to environmental factors to explain this rising prevalence (3). Parental influences, such as parental body mass index (BMI) and socio-economic status, are important risk factors in the socio-cultural environment $(4,5)$. Another potentially important socio-cultural factor, parenting style, is also receiving increased attention.

Parenting style (or general parenting) can be defined as 'a constellation of attitudes toward the child that are communicated to the child and that, taken together, create an emotional climate in which the parent's behaviours are expressed' (6). It is a concept consisting of three underlying dimensions: support, behavioural control and psychological control. Support (or involvement) refers to parental responsiveness and connectedness to the child. Behavioural (or strict) control refers to the regulation of the child's behaviour through firm and consistent discipline. Psychological control refers to the regulation of the child's behaviour through psychological means such as love withdrawal and guilt induction, e.g., behaving in a cool and unfriendly way when a child misbehaves or making a child feel guilty when he/she gets low grades in school. Psychological control is a more manipulative, suppressive form of

Correspondence: Mrs Gerda Rodenburg, IVO Addiction Research Institute, Heemraadssingel 194, 3021 DM Rotterdam, the Netherlands. Tel: +31 10 4253366. Fax: +31 10 2763988. Email: rodenburg@ivo.nl 
control (7-12) and therefore more likely to undermine the child's autonomy and ability to self-regulate behaviours, including food intake (13).

Researchers usually operationalize general parenting in two dimensions: support and behavioural control $(6,7)$. However, they tend to neglect the dimension of psychological control (see Barber [14]), also when exploring the relationship between parenting and child weight. These studies, of which there are very few, have produced inconsistent results, as demonstrated in recent reviews $(15,16)$. To clarify such inconsistent and equivocal findings, researchers have increasingly called for the dimension of psychological control to be included in parenting research $(14,17-20)$. Therefore, the first aim of this study was to examine whether adding 'psychological control' to the generally accepted parenting dimensions of 'support' and 'behavioural control' would help to clarify the association between parenting and child weight. In studies relating parenting to children's behaviours, authoritative parenting (a way of parenting that combines high support with high behavioural control) was found to be a protective factor for problem behaviours (21). Because health risk behaviours, overweight and obesity can be seen as problem behaviours, we hypothesized that the parenting dimensions support and behavioural control, and the authoritative parenting style, would negatively correlate with child overweight. Because psychological control is seen as a risk factor for problem behaviour $(19,21)$, we hypothesized that psychological control and the rejecting parenting style (characterized by high psychological control, low support and low behavioural control) would be positively associated with child overweight.

Apart from the growing obesity pandemic, several studies showed socio-economic differences in overweight $(4,5)$. In industrialized countries, low socio-economic status (SES) groups and minority groups had a higher prevalence of obesity (22-25), implying a particular need for research in these groups. In their review, Ventura and Birch suggested that the relationship between parenting and child weight could be clarified by including moderating factors in the analyses (15). Therefore, our second aim was to establish whether the potential association between parenting and child weight is moderated by socio-demographic factors, such as child age, child ethnicity and parent's education.

\section{Methods}

\section{Study design and procedure}

To achieve our research aims, a cross-sectional study was conducted as part of the longitudinal
INPACT study, which consists of 1,840 parentchild dyads. INPACT (IVO Nutrition and Physical Activity Child cohorT) is an observational study, initiated in 2008, focusing on modifiable determinants of overweight in the micro-environment of children in the Netherlands, aged 8-12 years.

After approval for the INPACT study was obtained from the Ethical Committee of the Erasmus Medical Center, the first wave of data collection took place in the autumn of 2008 at Dutch primary schools in southern Netherlands (Eindhoven area). In recruiting the schools we collaborated with the Municipal Health Authority for Eindhoven and surrounding area (GGD Brabant-Zuidoost). The Municipal Health Authority invited all general primary schools in their service area to participate in the INPACT study. Of the 265 invited schools, 91 took part. There was an equal response rate from rural and urban schools. The primary caregivers of third-grade students (aged about 8 years) were invited to participate in the cohort study, together with their child. Of the 2,948 parent-child dyads invited, $1,840(62.4 \%)$ gave informed consent to participate in the INPACT study over a four-year period.

The present study was based on the first wave of data collection, in which qualified research assistants measured the children's height and weight at school. The primary caregiver filled in a questionnaire at home, recording data on dietary and physical activity behaviours, and potentially relevant home environmental factors, including the three parenting dimensions, parental BMI and socio-demographic variables. Of the 1,840 participating parent-child dyads, 1,665 were included in the present study. We excluded underweight children $(6.3 \%)$ and children with no or invalid data on the child BMI outcome measure $(3.2 \%)$. Underweight children were excluded to prevent distortion of the results. International cut-off scores were used to determine whether a child was underweight (26).

\section{Sample characteristics}

Based on international cut-off scores (26), 11.8\% of the 1,665 participating children were overweight and $3.5 \%$ obese. Most of the participating children were aged $8(76.9 \%)$ or $9(20.1 \%)$ years. Boys $(51 \%)$ and girls $(49 \%)$ were represented in almost equal numbers. Most of the primary caregivers who completed the questionnaire were female $(92 \%)$ and lived with a partner (91\%). Of the primary caregivers, $21 \%$ had finished education at a low level (primary school and lower vocational/lower general secondary education), $46 \%$ at medium level (intermediate vocational education, higher general secondary 
education and university prep) and 33\% at a high level (higher vocational education and university). Over $15 \%$ of the children were from a non-Dutch ethnic background, with one or both parents born abroad: $9 \%$ from non-Western countries $(n=152)$; $7 \%$ from Western countries $(n=123)$.

\section{Measurements}

\section{Parenting style}

The parenting style of the primary caregiver was measured using the Dutch translation (27) of an instrument based on earlier work by Steinberg et al. $(7,28)$. This 22 -item measure assessed three parentingstyle dimensions (support, behavioural control and psychological control) using a response scale ranging from -2 (completely disagree) to +2 (completely agree). Support was measured with seven items, such as 'When my child gets a low grade in school, I offer to help him/her' $(\alpha=0.71)$. These items were combined in one variable by summing the item scores [range -14 (low) to +14 (high)]. Behavioural control was also measured with seven items, such as 'I know exactly what my child does in his/her free time' and 'I try to know where my child goes after school' $(\alpha=0.72)$. As recommended by Stattin and Kerr (29), behavioural control measured both parental knowledge and behavioural monitoring. After summing the item scores, the behavioural control variable ranged from -14 (low) to +14 (high). Psychological control was measured with eight items, such as 'I make my child feel guilty when he/she gets a low grade in school' $(\alpha=0.72)$. This variable ranged from -16 (low) to +16 (high).

Based on these three parenting dimensions, five parenting styles have been established: the authoritative (high support, high behavioural control, low psychological control), permissive (high support, low behavioural control, low psychological control), authoritarian (low support, high behavioural control, low psychological control), rejecting (low support, low behavioural control, high psychological control), and neglecting (low support, low behavioural control, low psychological control) parenting style (e.g., [30]). In addition to the separate dimensions we constructed these five parenting styles by dichotomising the sample on each dimension (median split) and examining the three variables simultaneously.

\section{Socio-demographic variables}

Measured socio-demographic variables included child's gender, age and ethnicity, as well as family structure and primary caregiver's education level (all assessed in the questionnaire completed by the primary caregiver). Child ethnicity was defined by the parents' country of birth, according to standard procedures of Statistics Netherlands (31). If both parents were born in the Netherlands the child was classified as native Dutch, if at least one parent was born outside the Netherlands but inside Europe, including former Yugoslavia and Soviet Union, North America, Oceania, Indonesia or Japan, the child was classified as a Western immigrant, and if at least one parent was born in Turkey, Africa, Latin America or Asia the child was classified as a nonWestern immigrant. By differentiating between Western and non-Western immigrants we tried to cover cultural differences that may substantially influence behaviour (32). Family structure indicated whether the child lived in a family with one parent (primary caregiver only) or with two (primary caregiver plus spouse/partner). The education level of the primary caregiver was defined as low (primary school and lower vocational/lower general secondary education), medium (intermediate vocational education, higher general secondary education and university prep) or high (higher vocational education and university), according to international classification systems (33).

\section{Parental BMI}

The primary caregiver reported his/her own height and weight and that of his/her partner. He/she also reported whether he/she and the partner were the child's biological parents. Maternal and paternal BMI (for biological parents only) were calculated on the basis of their answers ( $n_{\text {maternal BMI }}=1568$; $\mathrm{n}_{\text {paternal BMI }}=1380$ ).

\section{Child BMI (z-scores)}

The outcome measure child BMI was based on the child's height and weight: i.e., weight $(\mathrm{kg}) /$ height $(\mathrm{m})^{2}$, as measured by the qualified research assistants. Children were measured at school according to standard procedures in light clothing without shoes, to the nearest $0.1 \mathrm{~kg}$ and $0.1 \mathrm{~cm}$. BMI z-scores were calculated (26) based on age and genderspecific values from the 1997 National Growth Study in the Netherlands (34). BMI z-scores were used in all analyses and indicate by how many standard deviations a child's BMI differs from the median $\mathrm{BMI}$ of the reference population for his/her age.

\section{Strategy for analyses}

To explore the relationship between parenting and child BMI z-scores, Pearson's correlations between the three parenting dimensions, maternal BMI, paternal BMI, the socio-demographic variables (child 
gender/age/ethnicity, family structure and educational level of primary caregiver) and child BMI $\mathrm{z}$-scores were computed. Variables that were correlated to both parenting dimensions and child BMI $\mathrm{z}$-scores were included in multivariate linear regression analyses as potential confounders (control variables).

For descriptive purposes, for parenting dimensions that were significantly associated with child BMI z-scores, average scores were calculated for each stratum of the socio-demographic variables. Differences between strata were analyzed with $t$-tests (child gender/age and family structure) or a oneway ANOVA (child ethnicity and educational level of primary caregiver).

Finally, multivariate linear regression analyses were performed to establish the relationship between parenting and child BMI z-scores. To determine whether separate parenting dimensions or parenting styles should be used as independent variables, we tested whether the three parenting dimensions interacted in relation to child BMI z-scores. If so, parenting styles would be used as independent variables in further regressions. We then tested: (a) whether parenting was correlated with child BMI z-scores, unadjusted and adjusted for parental BMI and socio-demographic variables, and (b) whether child age/ethnicity and educational level of the primary caregiver moderated the relationship. Moderation was tested by adding interaction terms to the regression analyses (significance level: 0.05). As missing data on socio-demographic variables and parental BMI were not imputed, 1,307 parentchild dyads were included in the regression analyses.

\section{Results \\ Descriptives}

Table I shows that psychological control is the only parenting dimension that was significantly associated with child BMI z-scores $(r=0.088 ; p<0.01)$. The parenting dimension 'support' was negatively correlated with psychological control and positively correlated with behavioural control. Maternal and paternal BMI were positively correlated with both psychological control and child BMI, and were thus potential confounders. The socio-demographic variables child ethnicity (non-Western immigrants vs. native Dutch) and primary caregiver's education level were also related to psychological control and child BMI, and therefore also control variables.

Analyses of average scores on psychological control showed that primary caregivers of children aged 9 and 10 years reported significantly more psychological control $($ mean $=-6.03 ; \mathrm{SD}=4.41 ; n=340)$

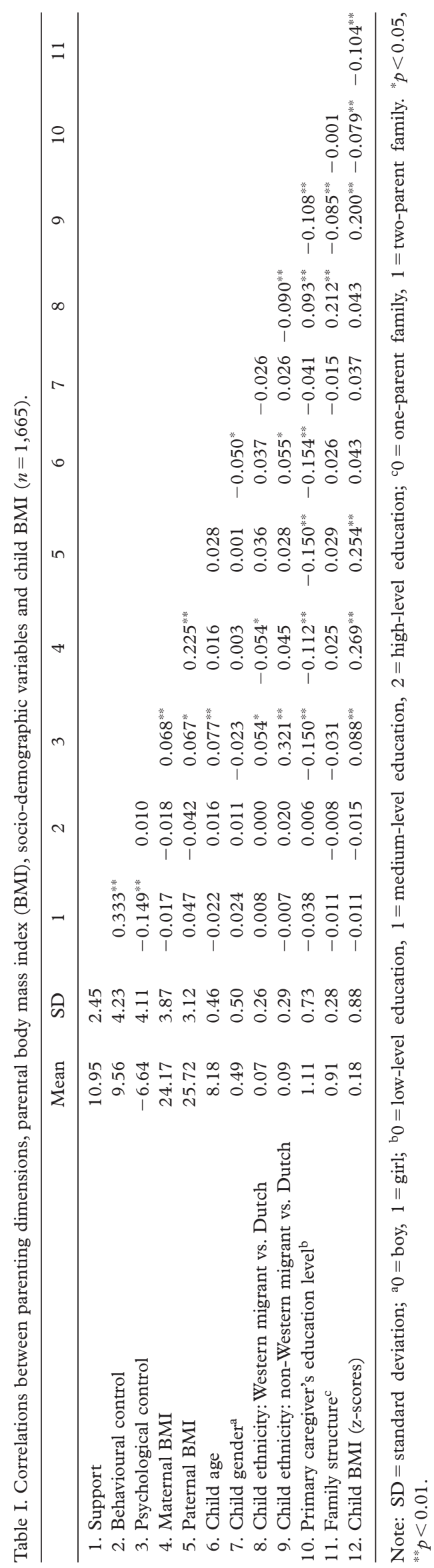


than those of children aged 7 and 8 years $($ mean $=-6.80 ; \mathrm{SD}=4.01 ; n=1324)(t=-3.11$; $\mathrm{df}=1662 ; p=0.002)$. Primary caregivers of native Dutch children reported significantly less psychological control $($ mean $=-7.16 ; \mathrm{SD}=3.56 ; n=1390)$ than those of non-Western (mean $=-2.48 ; \mathrm{SD}=5.49$; $n=152$ ) and Western (mean $=-5.85 ; \mathrm{SD}=4.82$; $n=123)$ immigrants $(\mathrm{F}=102.81 ; \mathrm{df}=2 ; p<0.001)$. Similarly, high-educated primary caregivers reported significantly less psychological control (mean $=-7.38$; $\mathrm{SD}=3.64 ; n=520)$ than those of medium-educated (mean $=-6.73 ; \mathrm{SD}=4.09 ; n=737)$ and loweducated primary caregivers $($ mean $=-5.67 ; \mathrm{SD}=$ $4.40 ; n=343)(\mathrm{F}=18.89 ; \mathrm{df}=2 ; p<0.001)$. There were no significant differences in psychological control between boys and girls, or between one-parent and two-parent families.

\section{Multivariate linear regression analyses}

As the interaction term for support, behavioural control and psychological control was significantly correlated with child BMI z-scores $(p=0.011)$, we proceeded with regression models in which the association between parenting styles (instead of separate parenting dimensions) and child BMI z-scores were tested. In the first set of regression analyses we tested whether parenting styles were correlated with child BMI z-scores, unadjusted and adjusted for potential confounders. Table II shows that rejecting parenting is the only parenting style that was significantly related to child BMI z-scores $(\beta=0.101$; $p<0.001$, model 1), also when adjusted for parental $\mathrm{BMI}$, child ethnicity and primary caregiver's education level $(\beta=0.074, p<0.01$, model 2$)$. In the adjusted model, maternal BMI, paternal BMI and child ethnicity (non-Western immigrant vs. native Dutch) were statistically significant. Inclusion of the control variables increased the explained variance of the model by about $15 \%$.

In the second set of regression analyses we tested whether socio-demographic variables moderated the relationship between rejecting parenting and child BMI. Separate interaction terms for child ethnicity, child age and primary caregiver's education level were added to the regression equation. None of the interaction terms was significant.

\section{Discussion}

This study shows that 'psychological control' explains a part of the association between parenting and child weight. The finding that rejecting parenting - the only parenting style that is characterized by high psychological control - was associated with a higher child BMI underlines the importance of including psychological control in parenting measures in the study of childhood overweight. Including moderating influences in the analyses did not clarify the relationship between parenting and child weight.

As demonstrated in the review by Ventura and Birch, research on parenting and child weight that took into account the parenting dimensions support and behavioural control has produced inconsistent

Table II. Results of multivariate linear regression analyses of parenting style on child body mass index (BMI), adjusted for parental BMI and socio-demographic variables $(n=1,307)$.

\begin{tabular}{|c|c|c|c|c|}
\hline \multirow[b]{2}{*}{ Variable } & \multicolumn{2}{|c|}{ Child BMI: model $1^{\mathrm{a}}$} & \multicolumn{2}{|c|}{ Child BMI: model $2^{\mathrm{b}}$} \\
\hline & $\beta$ & $\mathrm{R}^{2}$ & $\beta$ & $\mathrm{R}^{2}$ \\
\hline $\begin{array}{l}\text { Rejecting parenting }(n=239) \\
\text { (low support, low behavioural control, } \\
\text { high psychological control) }\end{array}$ & $0.101^{* * *}$ & 0.010 & $0.074^{* *}$ & 0.155 \\
\hline $\begin{array}{l}\text { Authoritative parenting }(n=252) \\
\text { (high support, high behavioural control, } \\
\text { low psychological control) }\end{array}$ & -0.044 & 0.002 & -0.014 & 0.149 \\
\hline $\begin{array}{l}\text { Permissive parenting }(n=230) \\
\text { (high support, low behavioural control, } \\
\text { low psychological control) }\end{array}$ & -0.042 & 0.002 & -0.037 & 0.151 \\
\hline $\begin{array}{l}\text { Authoritarian parenting }(n=125) \\
\text { (low support, high behavioural control, } \\
\text { low psychological control) }\end{array}$ & -0.029 & 0.001 & 0.000 & 0.149 \\
\hline $\begin{array}{l}\text { Neglecting parenting }(n=221) \\
\text { (low support, low behavioural control, } \\
\text { low psychological control) }\end{array}$ & -0.006 & 0.000 & 0.017 & 0.149 \\
\hline
\end{tabular}

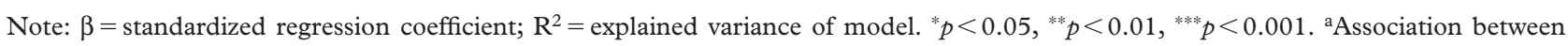
parenting style, e.g., rejecting vs. non-rejecting, and child BMI (z-scores). ${ }^{\mathrm{b}}$ Model $1+$ adjusted for maternal BMI, paternal BMI, child ethnicity (Western migrant vs. Dutch and non-Western migrant vs. Dutch) and primary caregiver's education level (medium-level vs. low level and high-level vs. low-level). 
findings (15). However, these studies used different measures of parenting style, different methods of data collection and were largely cross-sectional in design. The only longitudinal study in their review showed that authoritative parenting had a preventive influence on overweight. A recent longitudinal study of Berge et al. (35) showed a similar result: maternal authoritative parenting predicted lower $\mathrm{BMI}$ in sons and daughters. Authoritative parenting is also reported to be a protective factor for other problem behaviours (21). Although we hypothesized that the parenting dimensions of support and behavioural control, and the authoritative parenting style would negatively correlate with child weight, they were in fact not correlated. The present study indicates that psychological control may be a crucial dimension within parenting research, and that parenting style should be measured three-dimensionally $(14,17-20)$.

Because researchers have tended to neglect the dimension of psychological control in studies on the relationship between parenting and child weight, our results on psychological control could be compared with only one study. In their cross-sectional study, Zeller et al. (36) found no relationship between psychological control and child BMI. However, they used a different measure of parenting style and conducted their study in a clinical setting compared to our community sample.

Because broader parenting research has shown psychological control to be a risk factor for problem behaviours (21), and an indicator for poor parenting quality (27) we hypothesized that psychological control would be positively associated with child weight. The positive association of rejecting parenting with child BMI may indicate that strong parental psychological control is a potential risk factor for child overweight. Note that psychological control is a distal factor, which is expressed in the small effect size of the association and low variance explained.

The reasons for the potential risk of psychological control on overweight need to be further explored. Adjustment for parental BMI, ethnicity and parent's education level did not alter the relationship substantially, suggesting that the association between rejecting parenting and child BMI is not driven by unmeasured variables that have to do with cultural influences. Psychological control is suppressive and more likely to undermine a child's autonomy and ability to self-regulate matters such as food intake (13). Emotional eating might be linked to psychological control and overweight. Indeed, Snoek et al. (17) found adolescent's reports of high psychological control to be associated with higher emotional eating. Emotional eating, in turn, is reported to be related to higher BMI z-scores in children $(37,38)$.
It is important to include the potential mediating role of children's eating style and parental feeding style in future studies $(15,39)$.

Barber et al. studied psychological control in adolescent samples and found no empirical evidence indicating at what age psychological control becomes a reliable and stable aspect of parental control (40). We tested the moderating effect of child age, which was non-significant. However, in our sample the age range was $8-10$ years; the age effect on psychological control might have become apparent had our sample covered a broader age range, or if the relationship had been studied longitudinally (which is suggested for future studies).

Recently, Topham et al. (41) tested the moderating influence of SES on the association between parenting style and child BMI, and concluded that SES interacts with permissive parenting to predict child obesity. This finding underlines that socioeconomic subcultures should not be ignored in the study of childhood obesity (42). Although we did not find moderation effects of child ethnicity and primary caregiver's education level, in the adjusted analyses a non-Western ethnicity was significantly and positively associated with child weight, stressing that more insight is also needed into ethnic subcultures to improve the focus of programs aimed at reducing overweight.

\section{Strengths and limitations}

Our study emphasizes the need for studies on parenting to include the impact of psychological control on child weight. To our knowledge, our study is only the second one to have taken psychological control into account when examining the association between parenting and child weight (36), and the first that makes use of the rejecting parenting style. In addition, rather than using self-administered data, we measured the children's height and weight to calculate their BMI. Finally, we could overcome the shortcoming of previous studies that did not adjust for maternal/paternal BMI (15). The importance of including these potential confounders is illustrated by the fact that, in this study, maternal/paternal BMI were most strongly correlated with child BMI.

A limitation of our study is the cross-sectional design. Child weight might influence the parent's way of parenting, or the relationship between parenting and child weight might be bi-directional. To further elucidate cause and effect, a longitudinal study design is needed. Recent longitudinal studies on the relationship between parenting and child weight have shown that parenting influences child weight $(35,43)$. As parenting is defined as a general constellation of attitudes, rather than attitudes specifically 
related to diet and physical activity, we assume bi-directionality will more likely be found in the relationship between more specific parental feeding practices and child weight.

Another limitation of the present study is that we measured parenting style using the Dutch translation (27) of an instrument based on earlier work by Steinberg et al. $(7,28)$, which has not been validated in a Dutch sample. However, the instrument is frequently used in many studies worldwide $(27,44-46)$ and shows good internal consistency $(\alpha>0.7)$. In addition, we measured parenting style in one parent, and not in both $(47,48)$. However, we asked the primary caregiver to report on parenting, assuming that the primary caregiver is the most committed to child rearing.

Finally, one third of the invited schools and $62 \%$ of the invited parent-child dyads participated in our study. As mentioned before, the school response rate was equal among rural and urban schools. Moreover, the prevalence of overweight and obesity in our sample was comparable to Dutch prevalence rates among children. Therefore, we believe that our sample was a good representation of parents and their children, and that the results are not biased through selective participation.

\section{Conclusion}

By adding the dimension of psychological control to the concept of parenting, this study has elucidated the mechanisms whereby parenting may affect child weight. By showing that 'rejecting parenting' is associated with a higher child weight, we stress the need for longitudinal research in which parenting style is measured three-dimensionally. Potential mediating effects of parental feeding style and children's eating style, as well as age moderation, should be included in these studies.

\section{Acknowledgements}

Financial support for the INPACT study was provided by ZonMw, the Netherlands Organisation for Health Research and Development (grant ID no. 121010011). All research by G. Rodenburg is financed by IVO Addiction Research Institute Rotterdam and by the Department of Public Health, Erasmus Medical Center Rotterdam. None of the funding sources had any influence on the data analyses, interpretation and presentation.

Declaration of interest: The authors report no conflicts of interest. The authors alone are responsible for the content and writing of the paper.

\section{References}

1. van den Hurk $K$, van Dommelen $P$, van Buuren $S$, Verkerk PH, HiraSing RA. Prevalence of overweight and obesity in the Netherlands in 2003 compared to 1980 and 1997. Arch Dis Child. 2007;92(11):992-5.

2. Kosti RI, Panagiotakos DB. The epidemic of obesity in children and adolescents in the world. Cent Eur J Public Health. 2006;14(4):151-9.

3. Swinburn B, Egger G, Raza F. Dissecting obesogenic environments: the development and application of a framework for identifying and prioritizing environmental interventions for obesity. Prev Med. 1999;29(6):563-70.

4. Thorn J, Waller $M$, Johansson $M$, Mårild $S$. Overweight among four-year-old children in relation to early growth characteristics and socioeconomic factors. J Obes. 2010: 23-9.

5. Danielzik S, Czerwinski-Mast $M$, Langnäse $K$, Dilba $B$, Müller MJ. Parental overweight, socioeconomic status and high birth weight are the major determinants of overweight and obesity in 5-7-y-old children: baseline data of the Kiel Obesity Prevention Study (KOPS). Int J Obes Relat Metab Disord. 2004;28(11):1494-502.

6. Darling N, Steinberg L. Parenting style as context: An integrative model. Psychol Bull. 1993;113:487-96.

7. Steinberg L, Elmen JD, Mounts NS. Authoritative parenting, psychosocial maturity, and academic success among adolescents. Child Dev. 1989:1424-36.

8. Baumrind D. Effects of authoritative parental control on child behavior. Child Dev. 1966;37(4):887-907.

9. Baumrind D. Current patterns of parental authority. Dev Psychol. 1971;4(1):1-103.

10. Maccoby EE, Martin JA. Socialization in the context of the family: parent-child interaction. In: Hetherington E, editor. Handbook of child psychology: socialization, personality and social development. New York, NY: Wiley; 1983: $1-101$.

11. den Exter Blokland EAW, Engels R, Finkenauer C. Parenting styles, self-control and male juvenile delinquency: the mediation role of self-control. In: Martinez M, editor. Prevention and control of aggression and the impacts on its victims. Secaucus, NJ: Springer; 2001:201-207.

12. Schachter S, Goldman R, Gordon A. Effects of fear, food deprivation, and obesity on eating. J Pers Soc Psychol. 1968; 10(2):91-97.

13. Birch LL, Fisher JO. Development of eating behaviors among children and adolescents. Pediatrics. 1998;101(3):539-49.

14. Barber BK. Parental psychological control: revisiting a neglected construct. Child Dev. 1996;67(6):3296-319.

15. Ventura AK, Birch LL. Does parenting affect children's eating and weight status? Int J Beh Nutr Phys Act. 2008; 5(1):15.

16. Sleddens EFC, Gerards SMPL, Thijs C, De Vries NK, Kremers SPJ. General parenting, childhood overweight and obesity-inducing behaviors: a review. Int J Pediatr Obes. 2011;6(2-2):e12-27.

17. Snoek HM, Engels RCME, Janssens JMAM, van Strien T. Parental behaviour and adolescents' emotional eating. Appetite. 2007;49(1):223-30.

18. Gray MR, Steinberg L. Unpacking authoritative parenting: reassessing a multidimensional construct. J Marriage Fam. 1999;61(3):574-87.

19. Barber BK, Harmon EL. Violating the self: parental psychological control of children and adolescents. In: Barber BK, editor. Intrusive parenting: how psychological control affects children and adolescents. Washington, DC, US: American Psychological Association. 2002:15-52. 
20. Steinberg L, Lamborn SD, Darling N, Mounts NS, Dornbusch SM. Over-time changes in adjustment and competence among adolescents from authoritative, authoritarian, indulgent, and neglectful families. Child Dev. 1994; 65(3):754-70.

21. Finkenauer C, Engels RCME, Baumeister RF. Parenting behaviour and adolescent behavioural and emotional problems: The role of self-control. Int J Behav Dev. 2005;29: 58-69.

22. Wang Y, Beydoun MA. The obesity epidemic in the United States - gender, age, socioeconomic, racial/ethnic, and geographic characteristics: a systematic review and metaregression analysis. Epidemiol Rev. 2007;29:6-28.

23. Wang Y, Zhang Q. Are American children and adolescents of low socioeconomic status at increased risk of obesity? Changes in the association between overweight and family income between 1971 and 2002. Am J Clin Nutr. 2006;84(4): $707-16$.

24. Sobal J, Stunkard AJ. Socioeconomic status and obesity: a review of the literature. Psychol Bull. 1989;105(2):260-75.

25. Ogden CL, Carroll MD, Curtin LR et al. Prevalence of overweight and obesity in the United States, 1999-2004. JAMA. 2006;295(13):1549-55.

26. Cole TJ, Bellizzi MC, Flegal KM, Dietz WH. Establishing a standard definition for child overweight and obesity worldwide: international survey. BMJ. 2000;320(7244):1240-6.

27. Beyers W, Goossens L. Emotional autonomy, psychosocial adjustment and parenting: interactions, moderating and mediating effects. J Adolesc. 1999;22(6):753-69.

28. Lamborn SD, Mounts NS, Steinberg L, Dornbusch SM. Patterns of competence and adjustment among adolescents from authoritative, authoritarian, indulgent, and neglectful families. Child Dev. 1991;62(5):1049-65.

29. Stattin H, Kerr M. Parental monitoring: a reinterpretation. Child Dev. 2000:1072-85.

30. Goossens L, Beyers W. Parenting style and adolescent adjustment: a two-year longitudinal study. Paper presented at 9th European Conference on Developmental Psychology, Island of Spetses, Greece.

31. Statistics Netherlands. Standaarddefinitie allochtonen. In: Hoe doet het CBS dat nou? Voorburg, The Netherlands; 2000:24-5.

32. Singh AS, Chinapaw MJ, Brug J et al. Ethnic differences in BMI among Dutch adolescents: what is the role of screenviewing, active commuting to school, and consumption of soft drinks and high-caloric snacks? Int J Behav Nutr Phys Act. 2009;6:23.

33. Eurostat. Task Force on Core Social Variables. Final Report. Luxembourg: European Communities; 2007.
34. Fredriks AM, Van Buuren S, Wit JM, Verloove-Vanhorick SP. Body index measurements in 1996-7 compared with 1980. Arch Dis Child. 2000;82(2):107-12.

35. Berge JM, Wall M, Loth K, Neumark Sztainer D. Parenting style as a predictor of adolescent weight and weight-related behaviors. J Adolesc Health. 2010;46:331-8.

36. Zeller $\mathrm{MH}$, Boles RE, Reiter-Purtill J. The additive and interactive effects of parenting style and temperament in obese youth seeking treatment. Int J Obes. 2008;32(10): 1474-80.

37. Sleddens EF, Kremers SP, Thijs C. The Children's Eating Behaviour Questionnaire: factorial validity and association with body mass index in Dutch children aged 6-7. Int J Behav Nutr Phys Act. 2008;5:49.

38. Viana V, Sinde S, Saxton JC. Children's Eating Behaviour Questionnaire: associations with BMI in Portuguese children. Br J Nutr. 2008;100(02):445-50.

39. Joyce JL, Zimmer-Gembeck MJ. Parent feeding restriction and child weight. The mediating role of child disinhibited eating and the moderating role of the parenting context. Appetite. 2009;52(3):726-34.

40. Barber B, Stolz H, Olsen J. Parental support, psychological control, and behavioral control: assessing relevance across time, culture, and method. Monogr Soc Res Child Dev. 2005; 70(4):1-137.

41. Topham GL, Page MC, Hubbs-Tait L et al. Maternal depression and socio-economic status moderate the parenting style/ child obesity association. Public Health Nutr. 2009:1-8.

42. Rhee KE, Lumeng JC, Appugliese DP, Kaciroti N, Bradley RH. Parenting styles and overweight status in first grade. Pediatrics. 2006;117(6):2047-54.

43. Rhee K. Childhood overweight and the relationship between parent behaviors, parenting style, and family functioning. Ann Am Acad Pol SS. 2008;615(1):11.

44. Pearson N, Atkin AJ, Biddle SJH, Gorely T, Edwardson C. Parenting styles, family structure and adolescent dietary behaviour. Public Health Nutr. 2010;13(08):1245-53.

45. Huver RME, Engels RCME, Vermulst AA, de Vries H. Is parenting style a context for smoking-specific parenting practices? Drug Alcohol Depen. 2007;89(2-3):116-25.

46. Kremers SPJ, Brug J, de Vries H, Engels R. Parenting style and adolescent fruit consumption. Appetite. 2003;41(1): 43-50.

47. Blissett J, Haycraft E. Are parenting style and controlling feeding practices related? Appetite. 2008;50(2-3):477-85.

48. Wake M, Nicholson JM, Hardy P, Smith K. Preschooler obesity and parenting styles of mothers and fathers: Australian national population study. Pediatrics. 2007;120(6): e1520. 